\title{
Correlation between Bisphenol A Exposure and Adverse Health Effects
}

\section{Michelle Kelley ${ }^{1,2}$, Armand G Ngounou Wetie ${ }^{1}$ and Costel C Darie ${ }^{1^{\star}}$}

${ }^{1}$ Biochemistry \& Proteomics Group, Department of Chemistry \& Biomolecular Science, Clarkson University, USA

${ }^{2}$ Department of Biology, Clarkson University, USA

\begin{abstract}
Bisphenol $A$ is found in polycarbonate plastics and epoxy resins that make up many items that people use every day such as water bottles, toys and food packaging. There is much disagreement about how much BPA exposure is necessary to cause adverse health effects. In a study completed by the EPA, they found that people have not been exposed to levels high enough to have an effect on their health. A study by the CDC found BPA in 95\% of the 394 of the adult urine samples tested, but impact human health is not yet clear. Many studies have found correlations between measurable amounts of BPA in the body and health effects including recurrent miscarriages, chromosomal abnormalities and polycystic ovarian syndrome. Exposure is particularly concerning in children, especially prenatal. This is because they have not yet developed UDP-glucuronosyltransferase, the primary BPA metabolizing enzyme. Also, studies of other species have found that unconjugated BPA can diffuse across the placenta, from a mother's circulation to the fetus. Several studies have focused on the detection and removal of BPA from the environment. There is still a lot of research to be done to determine safe levels of BPA exposure for adults, children and animals to avoid detrimental health risks.
\end{abstract}

Keywords: Bisphenol A; Estrogenic activity; Health impact

\section{Introduction}

Bisphenol A (BPA) is a chemical that is commonly used in the manufacturing of polycarbonate plastics and epoxy resins. It is a carbon- based synthetic compound that has the chemical formula $\left(\mathrm{CH}_{3}\right)_{2} \mathrm{C}\left(\mathrm{C}_{6} \mathrm{H}_{4} \mathrm{OH}\right)_{2}$. It is part of the group diphenylmethane derivatives and bisphenols. It contains two hydroxyphenyl groups.

The effect that BPA has on humans and the environment has been brought into question because it is a reproductive, developmental and systemic toxicant for animals [1]. It is also slightly estrogenic [1]. People are predominantly exposed to BPA through food packaging that is made using BPA, but it is also found in everyday objects including toys, medical equipment and dental monomers. Over 1 million pounds of BPA are released into the environment each year [1].

Standardized toxicity tests have been administered globally and have indicated that the levels that were found in humans and the environment were below levels that could cause potentially adverse effects. Several studies focusing on low doses have found subtle effects in laboratory animals at low concentrations. This is concerning for the environment because some of the concentration levels found during the experiment are close to the current environmental levels, which puts sensitive aquatic organisms at a high risk of adverse effects [1]. This has led to many studies on the effects of BPA and methods of removal of BPA from the environment [2-8].

\section{Scientific Studies Pertaining to BPA}

In mammals, estrogen receptors modulate many physical processes. Chemicals that have features similar to those of estrogens can interact with estrogen receptors and create biological responses that are similar to those caused by natural estrogens in the body. BPA is a structural analogue of estrogen and has the ability to bind to estrogen receptors [2]. BPA can be detoxified by the body and does not typically accumulate. It is a topic of debate whether or not serum concentrations of BPA in humans can be high enough to affect the normal estrogen related functions. One study found that most BPA concentrations are orders of magnitude less than what could be measured by modern analytical methods. They also found that BPA concentrations were below those required to occupy more than $0.0009 \%$ of Type II Estrogen Binding Sites, GPR30, ERa or ER $\beta$ receptors [2]. These results found limited to no potential for estrogenicity in humans. They also questioned the reports of measurable BPA in human serum, stating that an accurate analysis of BPA in serum is almost unachievable $[2,9]$.

\section{BPA Exposure in Humans}

In one study conducted in 2005 by the Center for Disease Control (CDC), the researchers found BPA in $95 \%$ of urine samples that were collected from 394 American adults and were tested using isotope dilution GC-MS $[3,10]$. Other studies focused on the exposure level to children. Researchers studied the potential exposures at home and at daycare for nine children and found that the average BPA exposure level for the young children was $42.98 \mathrm{ng} / \mathrm{kg} / \mathrm{day}[3,11]$. Another study focused on 257 preschool children and found that BPA was detected in more than $50 \%$ of indoor air, hand wipe, and food samples. They found that $99 \%$ of the exposure for the children was due to diet, about $52-74$ $\mathrm{ng} / \mathrm{kg} /$ day $[3,11]$.

\section{Health Effects of BPA on Adults}

In other studies the researchers focused on the health effects of BPA on adults, given that studies of the health effects of BPA on humans are very limited. Detectable BPA levels in the blood have been associated in women with conditions including obesity, endometrial hyperplasia, recurrent miscarriages, abnormal karyotypes and polycystic ovarian syndrome [3]. Three separate studies found connections between higher BPA exposure and health related impacts that could lead to chromosomal abnormalities [3]. One study found that women carrying fetuses with abnormal karyotypes had higher BPA serum than those

*Corresponding author: Costel C Darie, Biochemistry \& Proteomics Group, Department of Chemistry \& Biomolecular Science, Clarkson University, 8 Clarkson Avenue Potsdam, NY, 13699-5810, USA, Tel: 315-268-7763; Fax: 315-268-6610 E-mail: cdarie@clarkson.edu

Received December 11, 2014; Accepted January 20, 2015; Published January 23, 2015

Citation: Kelley M, Wetie AGN, Darie CC (2015) Correlation between Bisphenol A Exposure and Adverse Health Effects. Mod Chem appl 3: 147. doi:10.4172/23296798.1000147

Copyright: (C) 2015 Kelley M, et al. This is an open-access article distributed under the terms of the Creative Commons Attribution License, which permits unrestricted use, distribution, and reproduction in any medium, provided the original author and source are credited. 
carrying fetuses with normal karyotypes [3,12]. The only caveat about this study is the fact that maternal age was not controlled.

\section{Serum BPA Levels and Recurrent Miscarriages}

In a different study it was found that there is an association between serum BPA levels and recurrent miscarriages. In 45 women with a history of three or more consecutive first trimester miscarriages, they found mean BPA levels that were more than three times as high as the 32 women without fertility problems. Among 35 of the women that then became pregnant, there was some evidence of lower BPA in the women who had successful pregnancies as compared to the women who miscarried again. It is important to note that the median exposure levels of the two groups was identical and there were only a few women with high exposure levels $[3,13]$. Epidemiological studies like those have several limitations. The studies used small sample sizes, had limited detail relating to the subject selection criteria and limited control for potential cofounders. Also, because of the design of the experiments it was impossible to determine if the BPA metabolism was a secondary effect due to the conditions that were examined in the studies [3].

\section{The Impact of BPA on Children}

The impact of BPA is especially concerning in children. UDPglucuronosyltransferase is the primary phase $2 \mathrm{BPA}$ metabolizing enzyme. It is not present in the human fetus until after birth $[4,14]$. This is concerning because during the fetal development and early postnatal life through adolescence, there are critical periods of organ development. Exposure to endocrine disrupting chemicals during this time could have permanent adverse effects. Although not tested on humans, it was found through rodents, primates and other species that unconjugated BPA easily diffuses across the placenta from the mother's circulation and into the fetus [4,15-18].

\section{Effects of BPA on CYP19 or Aromatase}

One study looked at the effects of BPA on CYP19 or aromatase, which is highly expressed in placental cells. CYP19 catalyzes the conversion of estrogen from its precursors. In the study they focused on the effect of BPA in the transcription of CYP19 in JEG-3 cells [5]. JEG-3 cells are human choriocarcinoma cells that have a long lifespan and high proliferation activity [19].They found that the cells treated with BPA had reduced aromatase activity. Real time PCR was used to show that $5 \mu \mathrm{M}$ of BPA significantly reduced the mRNA expression in the cells. The proximal promoter region of exon I.1 in placental cells controls the activity of the CYP19 gene. The promoter activity of the gene fragment and exon-I.1 spliced mRNA abundance were also elevated. These results showed that BPA repressed the transcriptional control of promoter I.1. The study found that BPA could potentially reduce estrogen synthesis by down regulating CYP of placental cells [5].

\section{Adverse Health Effects of BPA Exposure}

Many other adverse health effects have been linked to exposure to BPA. Research on mice has found that prenatal exposure to BPA could potentially change the gross ovarian anatomy with a reduced number of corpora lutea. It could also lead to an increase in unilateral or bilateral blood filled ovarian bursae [5,20]. This is particularly concerning since BPA has been found in the serum of maternal and fetal plasma $[5,21,22]$. It has also been detected in placental tissue and breast milk [5]. Other researchers have found that BPA exposure increases the aneuploidy in oocytes or meiotic disturbances in mice. Also, aneuploidy of the ovum has been connected to miscarriages. This connection has also been seen in humans $[5,13]$.

One study involved the effect of BPA exposure in the reproduction of sheep. The study found that prenatal BPA treatment induced reproductive neuroendocrine defects, including Luteinizing Hormone (LH) excess and dampened LH surge as well as perturbed early ovarian gene expression [6]. During ovulation an LH surge causes the egg to move through the ovary wall and begin to move down the fallopian tube for fertilization within 24-36 hours of the LH surge [23]. They used three different BPA doses on pregnant sheep and found that none of the doses had an effect on the corpora lutea, progestogenic cycles, and mean number or duration of ovulatory or non-ovulatory follicles. Differences were found in the follicular count trajectories in all three follicle size classes of the prenatal BPA treated animals as compared to the controls. In the prenatal BPA-treated group, the number of follicular waves tended to be more variable, ranging from 2-5 follicular waves per cycle. The control group had 3 to 4 waves per cycle. The changes in the ovarian follicular dynamics paired with the defects in the time interval between estradiol rise and preovulatory LH release could likely lead to a subfertility in prenatal BPA- treated females [6].

\section{BPA Detection and Removal}

One such study focused on using multifunctional biocapsules to remove phenol and BPA from an environment. This method uses a biocapsule with an immobilized enzyme with a layer by layer configuration. The BPA is removed by enzymatically oxidizing the $\mathrm{BPA}$ and then the reaction product is bound onto a chitosan core biopolymer. This technique has several functions including the enzymatic breakdown of BPA, the use of the core material to absorb the degraded compound, colorimetric quantification and potential magnetic capabilities. These capsules have the capability to remove 5.6 ppm of BPA and up to $10 \mathrm{ppm}$ of phenol within 15 hours [7].

Another method developed to detect phenolic compounds such as BPA found that nickel nanoparticles can be used to construct electrochemical enzyme sensors. They used the nickel nanoparticles as an enzyme immobilization platform and electrode material and created a screen printing enzyme biosensor to detect the presence of BPA. The nickel biosensors were compared to the performance of the sensors based on iron oxide and gold nanoparticles. The three configurations were compared by their reproducibility, stability of more than 100 assays, and a wide linear range. Nickel was found to have a better detection limit and sensitivity than iron oxide or gold nanoparticles [8].

\section{Conclusion}

It has been found that BPA has the potential to have a wide range of health effects on humans and other organisms, especially involving reproductive health. There is still a lot of research to be done to determine what levels of BPA are safe for adults, children, and animals as well as the environment. Research also needs to be done on how to best detect and remove BPA from everyday products, especially related to food packaging and preparation. Lastly, it is important to find the best method to remove BPA from the environment.

\section{Acknowledgements}

Part of this work was supported by the Department of Chemistry \& Biomolecular Science. This manuscript was an extra credit paper requirement for the Biochemistry I class.

\section{References}

1. Bisphenol A (BPA) Action Plan Summary. Existing Chemicals, U. S Environmental Protection Agency. 
Citation: Kelley M, Wetie AGN, Darie CC (2015) Correlation between Bisphenol A Exposure and Adverse Health Effects. Mod Chem appl 3: 147. doi:10.4172/2329-6798.1000147

Page 3 of 3

2. Teeguarden J, Hanson-Drury S, Fisher JW, Doerge DR (2013) Are typical human serum BPA concentrations measurable and sufficient to be estrogenic in the general population? Food and Chemical Toxicology 62: 949-963.

3. Vandenberg LN, Hauser R, Marcus M, Olea N, Welshons WV (2007) Human exposure to bisphenol A (BPA). Reprod Toxicol 24: 139-177.

4. Vom Saal FS, Welshons WV (2014) Evidence that bisphenol A (BPA) can be accurately measured without contamination in human serum and urine, and that BPA causes numerous hazards from multiple routes of exposure. Mol Cell Endocrinol 398: 101-113.

5. Huang H, Leung LK (2009) Bisphenol A downregulates CYP19 transcription in JEG-3 cells. Toxicol Lett 189: 248-252.

6. Veiga-Lopez A, Beckett EM, Abi Salloum B, Ye W, Padmanabhan V (2014) Developmental programming: prenatal BPA treatment disrupts timing of LH surge and ovarian follicular wave dynamics in adult sheep. Toxicol App Pharmacol 279: 119-128.

7. Ispas CR, Ravalli MT, Steere A, Andreescu S (2010) Multifunctiona biomagnetic capsules for easy removal of phenol and bisphenol A. Water Res 44: 1961-1969.

8. Alkasir RS, Ganesana M, Won YH, Stanciu L, Andreescu S (2010) Enzyme functionalized nanoparticles for electrochemical biosensors: a comparative study with applications for the detection of bisphenol A. Biosens Bioelectron 26: $43-49$

9. Ye X, Zhou X, Hennings R, Kramer J, Calafat AM (2013) Potential externa contamination with bisphenol $A$ and other ubiquitous organic environmental chemicals during biomonitoring analysis: an elusive laboratory challenge. Environ Health Perspect 121: 283-286.

10. Calafat AM, Kuklenyik Z, Reidy JA, Caudill SP, Ekong J, et al. (2005) Urinary concentrations of bisphenol $A$ and 4-nonylphenol in a human reference population. Environ Health Perspect 113: 391-395

11. Wilson NK, Chuang JC, Lyu C, Menton R, Morgan MK (2003) Aggregate exposures of nine preschool children to persistent organic pollutants at day care and at home. J Expo Anal Environ Epidemiol 13: 187-202.

12. Yamada H, Furuta I, Kato EH, Kataoka S, Usuki Y, et al. (2002) Maternal serum and amniotic fluid bisphenol A concentrations in the early second trimester. Reprod Toxicol 16: 735-739.
13. Sugiura-Ogasawara M, Ozaki Y, Sonta S, Makino T, Suzumori K (2005) Exposure to bisphenol $A$ is associated with recurrent miscarriage. Hum Reprod 20: $2325-2329$

14. de Wildt SN, Kearns GL, Leeder JS, van den Anker JN (1999) Glucuronidation in humans. Pharmacogenetic and developmental aspects. Clin Pharmacokinet 36: $439-452$.

15. Gerona RR, Woodruff TJ, Dickenson CA, Pan J, Schwartz JM, et al. (2013) Bisphenol-A (BPA), BPA glucuronide, and BPA sulfate in midgestation umbilical cord serum in a northern and central California population. Environ Sci Technol 47: 12477-12485.

16. Miyakoda H, Tabata M, Onodera S, Takeda K (1999) Passage of bisphenol A into the fetus of the pregnant rat J Health Sci 45: 318-323.

17. Padmanabhan V, Siefert K, Ransom S, Johnson T, Pinkerton J, et al. (2008) Maternal bisphenol-A levels at delivery: a looming problem? J Perinatol 28 : 258-263.

18. Zalko D, Soto AM, Dolo L, Dorio C, Rathahao E, et al. (2003) Biotransformations of bisphenol $A$ in a mammalian model: answers and new questions raised by low-dose metabolic fate studies in pregnant CD1 mice. Environ Health Perspect 111: 309-319.

19. Hiden U, Wadsack C, Prutsch N, Gauster M, Weiss U, et al. (2007) The firs trimester human trophoblast cell line $\mathrm{ACH}-3 \mathrm{P}$ : a novel tool to study autocrine/ paracrine regulatory loops of human trophoblast subpopulations--TNF-alpha stimulates MMP15 expression. BMC Dev Biol 7: 137.

20. Markey CM, Coombs MA, Sonnenschein C, Soto AM (2003) Mammalian development in a changing environment: exposure to endocrine disruptors reveals the developmental plasticity of steroid-hormone target organs. Evol Dev 5: 67-75.

21. Ikezuki Y, Tsutsumi O, Takai Y, Kamei Y, Taketani Y (2002) Determination of bisphenol $A$ concentrations in human biological fluids reveals significant early prenatal exposure. Hum Reprod 17: 2839-2841.

22. Schönfelder G, Flick B, Mayr E, Talsness C, Paul M, et al. (2002) In utero exposure to low doses of bisphenol A lead to long-term deleterious effects in the vagina. Neoplasia 4: 98-102.

23. http://www.clearblueeasy.com/ovulation.php 